Check for updates

Cite this: RSC Adv., 2017, 7, 49105

\title{
Crystal structure transformation and step-by-step thermal decomposition behavior of dihydroxylammonium 5,5'-bistetrazole-1,1'- diolate $\uparrow$
}

\author{
Jianhui Jia, ab Yu Liu, ${ }^{b}$ Shiliang Huang, ${ }^{b}$ Jinjiang Xu, (D) *b Shichun Li, ${ }^{\text {b Haobin Zhang }}{ }^{\mathrm{b}}$ \\ and Xiong Cao*a
}

The crystal structure transformation and step-by-step thermal decomposition behavior of dihydroxylammonium 5,5'-bistetrazole-1,1'-diolate (TKX-50) under thermal stimulation were studied and the whole process included thermal expansion, primary decomposition and secondary decomposition. The thermal expansion and primary decomposition of TKX-50 were studied using in situ powder X-ray diffraction (in situ XRD) together with Rietveld refinement, by which the crystal structure transformation process can be accurately traced. The results showed that the thermal expansion of TKX-50 was anisotropic. In particular, the a-axis exhibited a negative thermal expansion (NTE) that may be attributed to the distortion of the six-membered ring, which results in $\mathrm{H}$-transfer between the cation and dianion. The crystal structure of the intermediate product after primary decomposition was also obtained. The secondary decomposition process was analysed using thermogravimetric-differential scanning calorimetry (TG-DSC) due to the safety risk of TKX-50 analyzed by in situ XRD. The crystal structure transformation process from TKX-50 to the intermediate product under heat stimulation was deduced. Meanwhile, the morphological change of the whole process was obtained using hot stage microscopy (HSM). Combined with TG-FTIR technology, the gaseous decomposition products at each step were analysed and the thermal decomposition mechanism of TKX-50 was proposed. This study further reveals the thermal decomposition behavior of TKX-50 and is helpful for better understanding the thermal decomposition mechanism.

\author{
Received 9th August 2017 \\ Accepted 8th October 2017 \\ DOI: $10.1039 / \mathrm{c} 7 \mathrm{ra0} 8816 \mathrm{~g}$ \\ rsc.li/rsc-advances
}

\section{Introduction}

The synthesis of high performance energetic materials with low sensitivity has become a long-term target for military and civilian applications. Compared with traditional CHON explosives, research of energetic ionic salts has shown major developments and energetic ionic salts have attracted wide attention due to their considerable properties. ${ }^{1-17}$ For example, energetic ionic salts have a higher positive enthalpy of formation due to the large number of $\mathrm{N}-\mathrm{N}$ and $\mathrm{N}-\mathrm{C}$ bonds, lower friction and impact sensitivity and better oxygen balance. Moreover, energetic ionic salts are environmental friendly due to the fact that the main decomposition gas is $\mathrm{N}_{2}$. As a typical energetic ionic salt, TKX-50 has attracted considerable attention. First of all,

${ }^{a}$ School of Environment and Safety Engineering, North University of China, Taiyuan, 030051, P. R. China.E-mail: cx92rl@163.com

${ }^{b}$ Institute of Chemical Materials, China Academy of Engineering Physics (CAEP), Mianyang,621900, P.R. China. E-mail: xujinjiang@caep.cn; Tel: +86-816-2493145

$\dagger$ Electronic supplementary information (ESI) available: IR, detailed structure description and CIFs. CCDC 1567754. For ESI and crystallographic data in CIF or other electronic format see DOI: $10.1039 / \mathrm{c} 7 \mathrm{ra} 08816 \mathrm{~g}$
TKX-50 is more insensitive. For example, the friction sensitivity $(120 \mathrm{~N})$ of TKX-50 is lower than that of $\beta$-HMX (112 N) and $\varepsilon$-CL$20(48 \mathrm{~N})$, and the impact sensitivity $(20 \mathrm{~J})$ of TKX-50 is also lower than that of TNT $(15 \mathrm{~J}), \operatorname{RDX}(7.5 \mathrm{~J}), \beta-\mathrm{HMX}(7 \mathrm{~J})$ and $\varepsilon$-CL$20(4 \mathrm{~J})$. At $298 \mathrm{~K}$, the crystal density of TKX-50 is close to that of $\beta$-HMX. The calculated detonation velocity of TKX-50 is $9698 \mathrm{~m} \mathrm{~s}^{-1}$ and the estimated detonation velocity is $9560 \pm$ $280 \mathrm{~m} \mathrm{~s}^{-1}$ in the new study, which is higher than that of TNT (7459 $\left.\mathrm{m} \mathrm{s}^{-1}\right)$, RDX (8983 $\left.\mathrm{m} \mathrm{s}^{-1}\right), \beta-H M X ~\left(9221 \mathrm{~m} \mathrm{~s}^{-1}\right)$ and $\varepsilon-C L-$ $20\left(9455 \mathrm{~m} \mathrm{~s}^{-1}\right) \cdot{ }^{18,19}$

Based on the excellent performance of TKX-50, a lot of research has been carried out. In particular, explosives and their components often need to be stored for quite a long time before use and the thermal decomposition reactions and the decomposition mechanism of explosives are very important to their stability. Fischer ${ }^{20}$ firstly studied the thermal behavior of TKX50 using differential scanning calorimetry (DSC) and thermogravimetric analysis (TGA). It was found that the thermal decomposition process includes two stages and the first stage starts at $210-250{ }^{\circ} \mathrm{C}$ depending on the heating rate. The decomposition kinetic parameters of TKX-50 have been 
calculated mainly using Kissinger and Ozawa's method and the results were in different ranges depending on the test condition. ${ }^{21-23,29}$ The structural stability and chemical stability of TKX50 under high pressure and high temperature were discussed based on Raman spectroscopy results and the intermediates at high pressure were attributed to a suppression of $\mathrm{H}$-transfer. ${ }^{24}$ The structural response of TKX-50 under high pressure was studied and the experimental results showed that TKX-50 exhibits a highly anisotropic compression, with an anomalous compression of the $a$-axis, which was explained by the hydrogen bonds. ${ }^{25}$

Regarding the primary thermal decomposition mechanism, Qi An found that proton transfer from the cation to the dianion decreases the reaction barrier and initiates decomposition. ${ }^{26}$ Liya Meng studied the influences of strong hydrogen bonds on the stability of TKX-50 and found that strong hydrogen bonds easily promote H-transfer, which accelerates thermal decomposition. ${ }^{27}$ Sinditskii further investigated the thermal decomposition under non- and isothermal conditions, proposed the thermal decomposition mechanism of TKX-50 and found that the free hydroxylamine formed in the dissociation reaction determines the decomposition of TKX-50. What's more, he inferred that diammonium 5,5'-bistetrazole-1, $1^{\prime}$-diolate (ABTOX) is an intermediate decomposition product based only on Fourier transform infrared spectroscopy (FTIR). ${ }^{28}$ Recently, Muravyev considered that the decomposition of bistetrazole diol (BTO) is the key process in the thermal decomposition of TKX-50, also proposed the thermal decomposition mechanism based on TGA and DSC and directly identified ABTOX to be the most important intermediate of the decomposition process. The authors found no trace of $\mathrm{H}_{2} \mathrm{O}$ in the first stage of TKX-50 decomposition. ${ }^{29}$ Zhipeng $\mathrm{Lu}$ found that a phase transition facilitates $\mathrm{H}$-transfer and produces final small stable molecules including $\mathrm{NH}_{3}$ and $\mathrm{H}_{2} \mathrm{O}$ based on Raman spectroscopy, thermogravimetric-differential scanning calorimetry (TG-DSC) and $a b$ initio calculations. In other words, the phase transition promotes the decomposition of TKX-50. ${ }^{30}$ However, accurate crystal structure information has not been obtained due to the limited temporal-spatial resolution of existing analytical methods and so further research is needed to observe the evolution process of related structures in situ.

Although the thermal decomposition behavior of TKX-50 has received extensive attention, the crystal structure transformation behavior has received less consideration. In particular, the behavior of the crystal structure from thermal expansion to thermal decomposition has not been studied, and the process of TKX-50 decomposition has mostly been studied using DSC, which analyses structural changes indirectly through thermal variation. However, on the DSC curve the partial heats of the exothermic process of the two-step decomposition overlap and it is difficult to distinguish the accurate thermal decomposition temperature of TKX-50. Additionally, the crystal structure change cannot be obtained using DSC. In particular, the crystal structure transformations from thermal expansion to primary decomposition to secondary decomposition are difficult to obtain by conventional DSC techniques. On the basis of previous work, in this paper, we have studied the thermal expansion behavior of TKX-50 using in situ XRD. It was found that anisotropic thermal expansion was the main process below $175{ }^{\circ} \mathrm{C}$, leading to a change of intermolecular force and the expansion and flipping of some molecules. In particular, the expansion along the $a$-axis is a negative thermal expansion, which results in a shorter distance between the cation and dianion, thus inducing hydrogen transfer. With the increasing temperature, primary decomposition occurred and was also observed dynamically using in situ $\mathrm{XRD}$, and the intermediate product was formed and confirmed as ABTOX by single crystal $\mathrm{X}$-ray diffraction, which was consistent with the conclusion of the literature. ${ }^{28,29}$ Additionally, the crystal morphology change due to the anisotropy during the thermal expansion of TKX-50 and the process from thermal expansion to primary decomposition were observed using hot stage microscopy (HSM). The secondary decomposition process was analysed using TG-DSC due to the safety risk of the in situ XRD. The secondary decomposition occurred at around $280{ }^{\circ} \mathrm{C}$. In addition, thermogravimetric-Fourier transform infrared spectroscopy (TG-FTIR) was applied to analyse the thermal decomposition gas products for each decomposition process. The thermal decomposition mechanism of TKX-50 was proposed and the related results further deepen the understanding of the relationship between the thermal stability and crystal structure of TKX-50.

\section{Experimental}

\subsection{Materials and instrumentation}

TKX-50 was provided by the Institute of Chemical Materials, China Academy of Engineering Physics and recrystallized by slow evaporation in water.

The powder X-Ray diffraction (PXRD) data were collected using a Bruker D8 Advance diffractometer using a Vantec detector with $\mathrm{Cu} \mathrm{K} \alpha$ radiation. The tube current and voltage were $40 \mathrm{~mA}$ and $40 \mathrm{kV}$ and the scan angle ranged from $10^{\circ}$ to $50^{\circ}$.

The single crystal X-ray diffraction data were collected using a Bruker APEX-II CCD diffractometer with Mo K $\alpha$ radiation at $296 \mathrm{~K}$. The structure was solved by Intrinsic Phasing with the ShelXT structure solution program and refined using Least Squares minimization by the XL refinement package.

\subsection{In situ structure transformation characterization using $\mathrm{X}$-ray diffraction}

In situ non-isothermal and isothermal powder X-ray diffraction were both carried out using a temperature programme. A TTK 450 temperature chamber was used to precisely control the temperature during the experiment. Non-isothermal in situ XRD was used to analyse the thermal expansion of TKX-50. The first scan started at $30^{\circ} \mathrm{C}$ and the next scan was conducted at a $10{ }^{\circ} \mathrm{C}$ interval. When the temperature reached $120{ }^{\circ} \mathrm{C}$, the scanning process changed to having a $5^{\circ} \mathrm{C}$ interval up to $175^{\circ} \mathrm{C}$. The final scan was carried out when the temperature was decreased to $30{ }^{\circ} \mathrm{C}$. 
Isothermal in situ XRD was used to analyse the primary decomposition of TKX-50. The first scan data were collected when the temperature was increased from ambient to $30{ }^{\circ} \mathrm{C}$, then the temperature was raised to $190{ }^{\circ} \mathrm{C}$ and the second scan was started after 10 minutes. The time interval was 10 minutes and after that a new scanning process was carried out. When such a process had been conducted 24 times, the temperature was decreased to $30{ }^{\circ} \mathrm{C}$ and the final data were collected. Except for the different target isothermal temperature, the same programme was applied for $192{ }^{\circ} \mathrm{C}, 194{ }^{\circ} \mathrm{C}, 196^{\circ} \mathrm{C}$ and $198^{\circ} \mathrm{C}$. The time point at which the target temperature had just been reached was used as a zero reference.

\subsection{In situ transformation observation using hot stage microscopy}

Hot stage microscopy (HSM) of TKX-50 was performed using a Linkam LTS420 Heating and Cooling Stage. The crystal was mounted on the hot stage and observed using a Scope.A1 optical microscope by ZEISS. The morphological changes of TKX-50 were obtained under heat stimulation. The temperature was set from $30{ }^{\circ} \mathrm{C}$ to $198{ }^{\circ} \mathrm{C}$ and the heating rate was $10{ }^{\circ} \mathrm{C} \mathrm{min}^{-1}$. When the temperature reached $198{ }^{\circ} \mathrm{C}$, this temperature was maintained for 210 minutes. After this the temperature was decreased to $30{ }^{\circ} \mathrm{C}$.

\subsection{Thermogravimetric techniques}

Thermogravimetric-differential scanning calorimetry (TG-DSC) technology was employed to analyse the secondary decomposition of TKX-50. The samples were obtained after the primary decomposition of TKX-50 using isothermal in situ XRD. The samples were tested in aluminum pans and the experiment was conducted at a heating rate of $10{ }^{\circ} \mathrm{C} \mathrm{min}{ }^{-1}$ from $30{ }^{\circ} \mathrm{C}$ to $400{ }^{\circ} \mathrm{C}$ with around $1.58 \mathrm{mg}$.

Thermogravimetric-Fourier transform infrared spectroscopy (TG-FTIR) was applied to analyse the gas products of each decomposition process. The temperature programme was set from $30{ }^{\circ} \mathrm{C}$ to $198{ }^{\circ} \mathrm{C}$ at a heating rate of $10{ }^{\circ} \mathrm{C} \mathrm{min}^{-1}$, the isothermal time was 60 minutes, and the temperature was then increased up to $500{ }^{\circ} \mathrm{C}$ at the same heating rate. Finally, the temperature was decreased to $30{ }^{\circ} \mathrm{C}$.

\subsection{Crystal structure refinement using the Rietveld method}

The Rietveld method in the TOPAS program of the Bruker Company was used to refine the obtained XRD diffraction patterns in order to obtain the lattice parameter changes and calculate the conversion degree influenced by the different temperatures. The instrument parameters used to analyse the lattice parameter changes are shown in Table 1 and the instrument parameters for calculating the conversion degree have been obtained from previous work. ${ }^{31}$ The fundamental principles of the Rietveld method have been mentioned in previous work. ${ }^{32}$
Table 1 Instrument parameters for Rietveld refinement

\begin{tabular}{lll}
\hline Instrument parameter & & Value \\
\hline \multirow{2}{*}{ Goniometer radius } & Primary & 217.5 \\
& Secondary & 217.5 \\
Equatorial convolutions & Receiving slit width $/ \mathrm{mm}$ & 0.1750585 \\
& FDS shape ${ }^{\circ}$ & 0.5 \\
Axial convolutions & Source length $/ \mathrm{mm}$ & 12 \\
& Sample length $/ \mathrm{mm}$ & 15 \\
& RS length $/ \mathrm{mm}$ & 12 \\
& Prim. soller $^{\circ}$ & 7.196213 \\
& Sec. soller ${ }^{\circ}$ & 3.753572
\end{tabular}

\section{Results and discussion}

\subsection{Morphological changes of TKX-50}

The morphological change process of TKX-50 under heat stimulation can be observed. From $30{ }^{\circ} \mathrm{C}$ to $175^{\circ} \mathrm{C}$, the crystal morphology remained basically unchanged. As the temperature increased to $198{ }^{\circ} \mathrm{C}$, the crystal appearance began to change slowly. It was found that cracks appeared on the crystal and liquid formed with bubbles emerging from the crystal. It was deduced that the crystal began to decompose but not fully. After
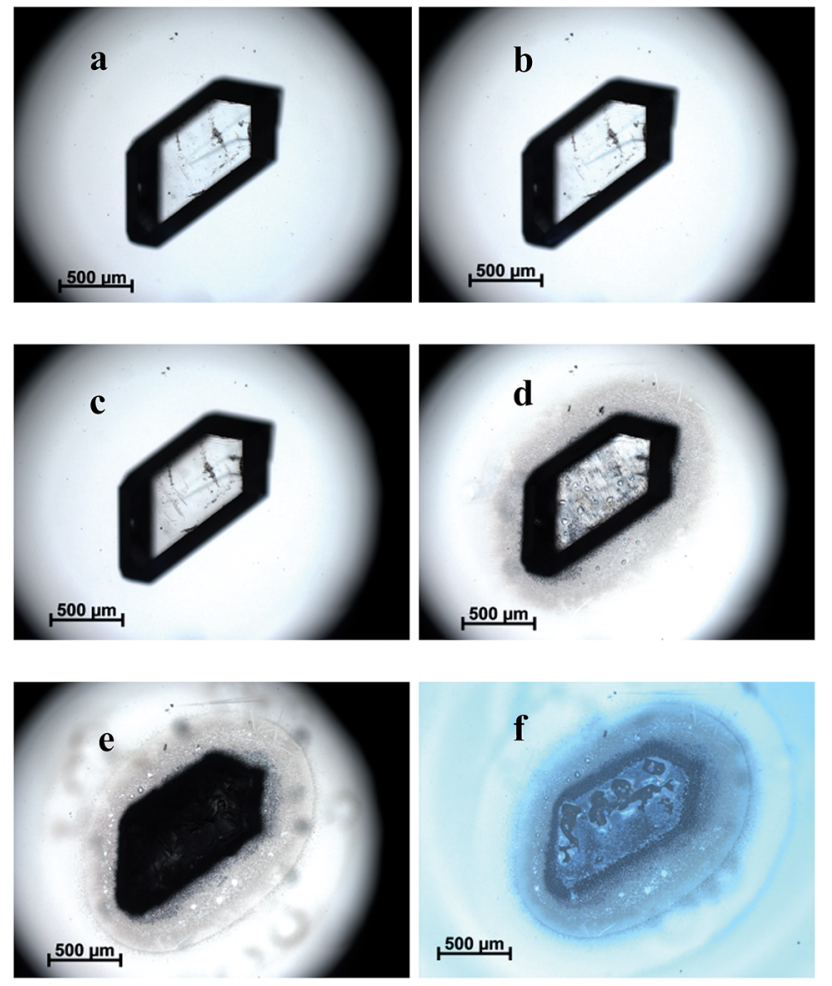

Fig. 1 The morphological changes of TKX-50 under heat stimulation. (a) The morphology of TKX-50 at $30{ }^{\circ} \mathrm{C}$; (b) the morphology of TKX-50 at $175^{\circ} \mathrm{C}$; (c) the morphology of TKX-50 when the temperature has just risen to $198{ }^{\circ} \mathrm{C}$; (d) the morphology of $\mathrm{TKX}-50$ when the temperature has risen to $198^{\circ} \mathrm{C}$ and been maintained for 1 hour; (e) the morphology of $\mathrm{TKX}-50$ after primary decomposition; (f) the morphology of TKX-50 after primary decomposition using the reflection mode of the microscope. 


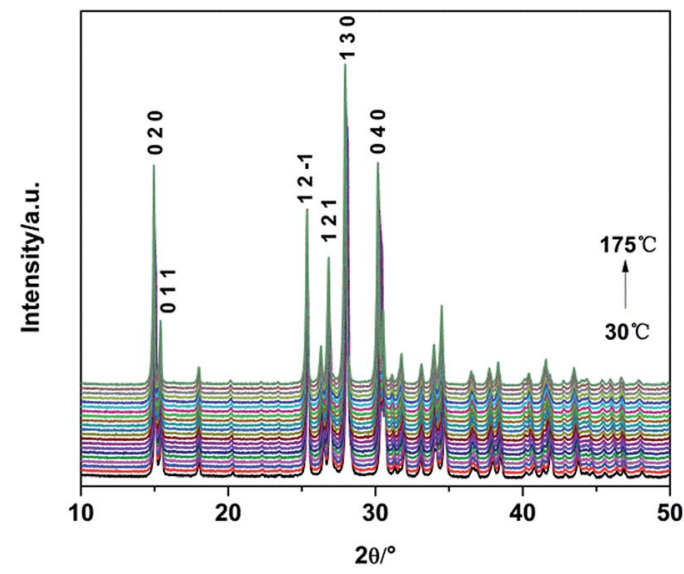

Fig. 2 XRD patterns of TKX-50 with increasing temperature from 30 to $175^{\circ} \mathrm{C}$.

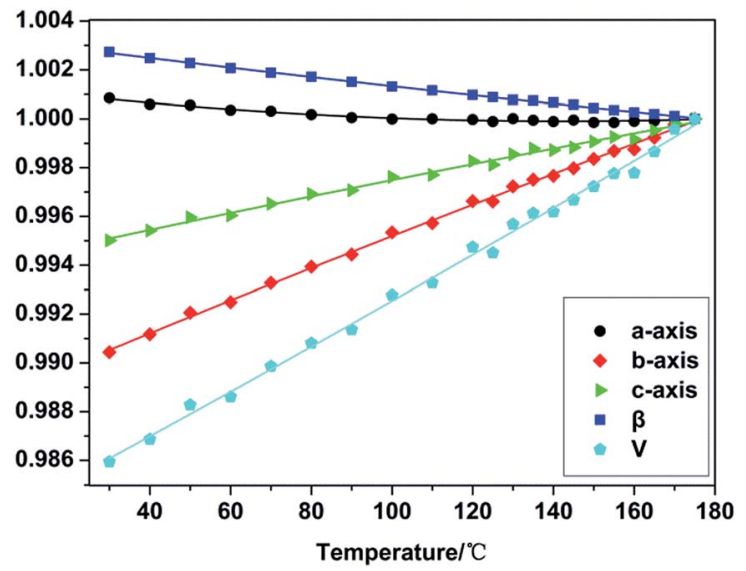

Fig. 3 Calculated unit cell parameters of TKX-50 normalized from 30 to $175^{\circ} \mathrm{C}$.

150 minutes, most of the crystal had decomposed leaving some solid residues. Meanwhile, the crystal turned from transparent to opaque and from a single crystal to polycrystalline. It was presumed that the primary decomposition of TKX-50 had occurred and a stable intermediate product was formed. The primary solid phase decomposition reaction of TKX-50 was started from local active spots of the crystal that appeared to form the reaction core, which destroyed the molecular structure at the active spots, and then extended gradually to the crystal interior. The detailed images of TKX-50 under heat stimulation are shown in Fig. 1.

\subsection{The thermal expansion of TKX-50}

In order to further confirm the crystal structure transformation and decomposition process of TKX-50 under thermal stimulation, in situ non-isothermal XRD was applied to investigate the thermal expansion of TKX-50. XRD patterns of TKX-50 were collected within the temperature range from $30{ }^{\circ} \mathrm{C}$ to $175{ }^{\circ} \mathrm{C}$ (Fig. 2). During the heating process the diffraction peaks in the XRD patterns shifted toward a lower $2 \theta$ without other obvious changes, which indicates that lattice expansion has taken place. Using the TOPAS software combined with Rietveld refinement, the refined lattice parameters of TKX-50 corresponding to certain temperature points could be obtained (detailed in Table $\mathrm{S} 1 \dagger)$ and the accurate thermal expansion coefficients were calculated. The refined lattice parameters of TKX-50 were expressed as a function of temperature.

It was found that the value of the $a$-axis decreased to a certain extent and then kept fluctuating with the increasing temperature. The $\beta$ angle also decreased with a $-0.27 \%$ change from $30{ }^{\circ} \mathrm{C}$ to $175{ }^{\circ} \mathrm{C}$. A negative thermal expansion (NTE) was exhibited. Meanwhile, it was observed that the value of the $b$ axis, $c$-axis and the unit cell volume all increased with the increasing temperature and the changes were $0.96 \%, 0.50 \%$ and $1.42 \%$, respectively, which shows positive thermal expansion (PTE). The normalized changing lattice parameters can be fitted to a second-order polynomial (Fig. 3). Meanwhile, the thermal expansion coefficients were calculated using the formula $\alpha=1 /$ $L(\mathrm{~d} L / \mathrm{d} T)$, in which $L$ represents the primary lattice constant. ${ }^{33}$ The average thermal expansion coefficients of the $a$-axis, $b$-axis, $c$-axis, $\beta$ angle and the unit cell volume were $-1.04635 \times 10^{-6}$, $5.56149 \times 10^{-6}, 4.76293 \times 10^{-6},-1.92479 \times 10^{-7}$ and $2.2973 \times$ $10^{-7}$, respectively. It was observed that the thermal expansion coefficient of each axis was different within the same temperature range. This revealed that the thermal expansion of TKX-50 was anisotropic. Corresponding to the morphology change from Fig. 1, although the anisotropy of the thermal expansion can lead to some change in crystal morphology, the anisotropic expansion will not cause significant change due to the fact that the crystal is in the state of free confinement, such as in cracking, grinding and so on.

\subsection{The primary decomposition of TKX-50}

In situ isothermal X-ray diffraction was used to carry out heat treatment of TKX-50 at 190, 192, 194, 196 and $198^{\circ} \mathrm{C}$. In order to eliminate the influence of the sample orientation on the diffraction peaks, the raw materials were completely ground before use. The heating program was then applied. Thus we obtained the whole process of crystal structure variation at different temperatures and compared this with the single crystal simulation XRD patterns of TKX-50 and ABTOX. The detailed processes are shown in Fig. 4 and the conversion degree of TKX-50 to the intermediate product at all the isothermal temperatures is shown in Fig. 5.

From the XRD patterns at $190{ }^{\circ} \mathrm{C}$ and $192^{\circ} \mathrm{C}$, it can be seen that the peaks shifted toward a lower $2 \theta$ due to thermal expansion and new weak peaks appeared with the increasing heating time. The intensity of the new peaks increased and that of the peaks belonging to the raw materials decreased obviously at $194{ }^{\circ} \mathrm{C}$. However, a small number of peaks of the raw TKX-50 still existed at $196{ }^{\circ} \mathrm{C}$. When the temperature rose to $198{ }^{\circ} \mathrm{C}$, the residual peaks of the raw material disappeared and new diffraction peaks appeared, in particular the (002) and (200) diffraction peaks. Moreover, the position of the new diffraction peaks coincided with the XRD pattern of ABTOX. We speculated that primary decomposition of TKX-50 occurred, but no 

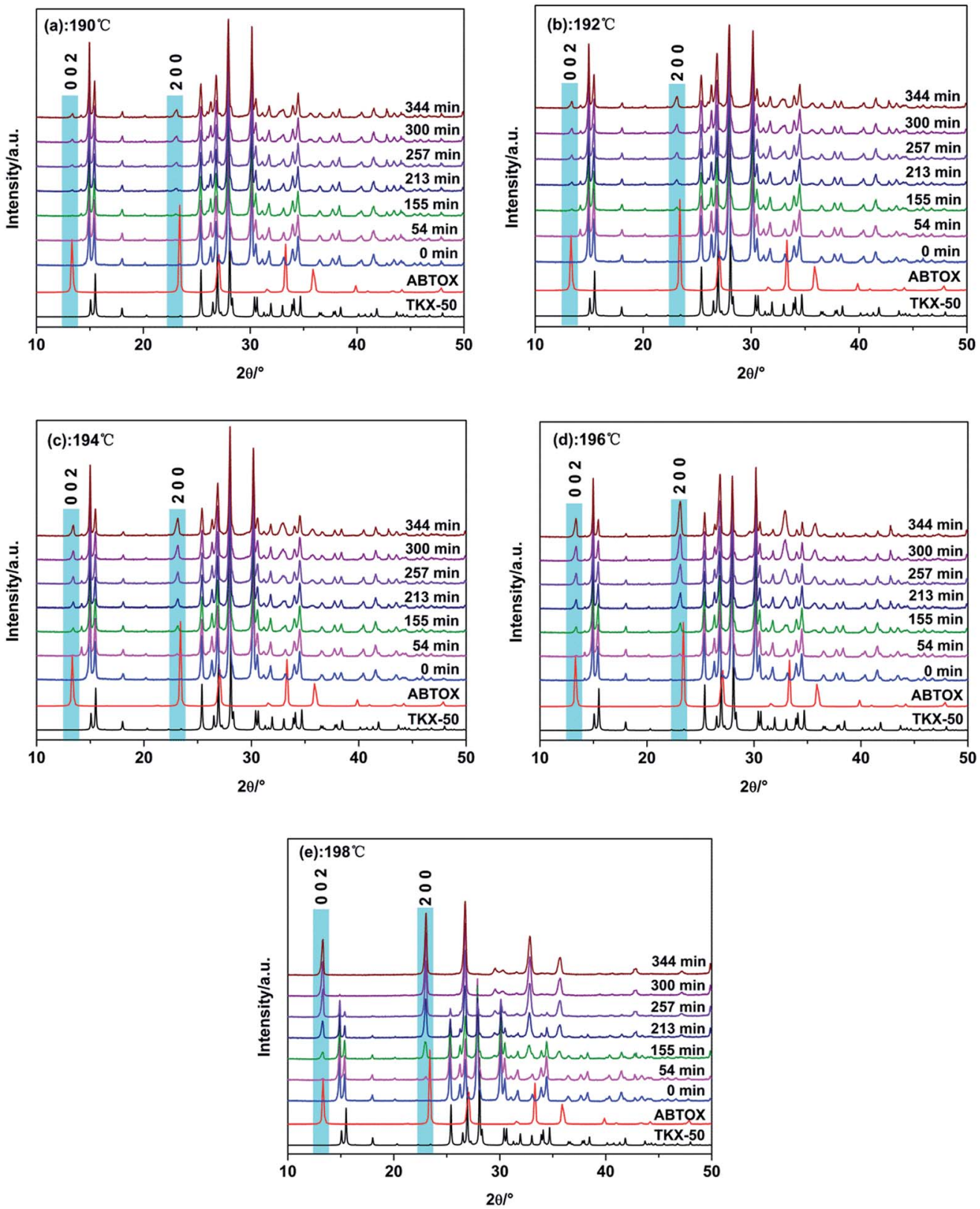

Fig. 4 (a-e) XRD patterns of TKX-50 at different isothermal temperatures.

crystalline transition occurred. Meanwhile, with increasing temperature the crystal structure changed more quickly. The results showed that the crystal structure changed under long time thermal stimulation. On the other hand, the XRD patterns at different temperatures were analysed and the conversion degrees for all the isothermal temperatures within the same time frame were all calculated. The final conversion degrees were $24.30 \%, 26.40 \%, 46.72 \%, 70.69 \%$ and $100 \%$ using the Rietveld method. With the increase of heating time, the conversion degree increased. The conversion degree was higher at higher isothermal temperatures for the same heating time. The results showed that TKX-50 and the intermediate product could coexist in a certain temperature range. As the heating time increased, primary decomposition gradually occurred and the intermediate product became stable.

Fourier transform infrared spectroscopy was utilized to analyse the main intermediate product (Fig. S1†). TKX-50 and the materials after in situ XRD at different constant temperatures were tested and the intermediate product was presumed to be ABTOX. The decomposed intermediate was then dissolved in water and the crystal was obtained by evaporation recrystallization. The structure of the main intermediate decomposition product was confirmed by single crystal XRD, and the results indicated that the intermediate product was ABTOX. The detailed characterization of ABTOX is shown in the ESI. $\dagger$ Corresponding to the morphology change from Fig. 1, the morphology changed during the primary decomposition 


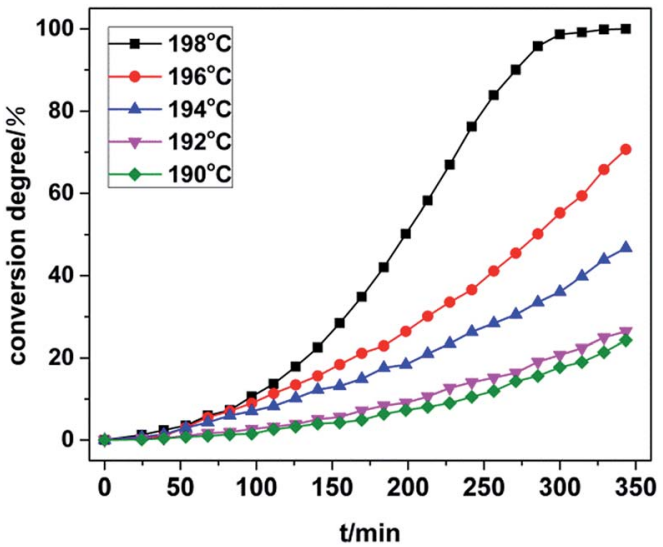

Fig. 5 Conversion degree of TKX-50 to the intermediate product at different isothermal temperatures.

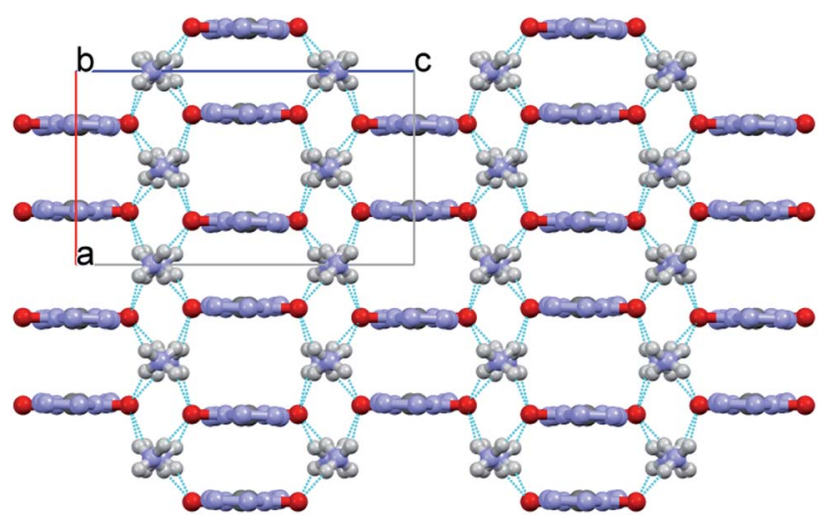

Fig. 6 The packing diagram of ABTOX viewed from the $b$-axis direction. The grey, white, red and blue balls represent $\mathrm{C}, \mathrm{H}, \mathrm{O}$ and $\mathrm{N}$ atoms, respectively.

Table 2 Hydrogen bond lengths $(\AA)$ and bond angles $\left(^{\circ}\right)$ for ABTOX

\begin{tabular}{|c|c|c|c|c|}
\hline $\mathrm{D}-\mathrm{H} \cdots \mathrm{A}$ & $d(\mathrm{D}-\mathrm{H}), \AA$ & $d(\mathrm{H} \cdots \mathrm{A}), \AA$ & $d(\mathrm{D} \cdots \mathrm{A}), \AA$ & $\underset{\circ}{\text { Angle }(\mathrm{D}-\mathrm{H} \cdots \mathrm{A})}$ \\
\hline N8-H8A $\cdots \mathrm{O} 1$ & 0.818 & 2.324 & 3.074 & 152.57 \\
\hline N8-H8B $\cdots \mathrm{O} 1$ & 0.862 & 2.041 & 2.902 & 178.99 \\
\hline 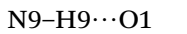 & 0.873 & 2.152 & 2.970 & 155.65 \\
\hline $\mathrm{N} 10-\mathrm{H} 10 \cdots \mathrm{O} 1$ & 0.873 & 2.160 & 2.970 & 154.05 \\
\hline
\end{tabular}

process. The crystal structure rearranged after the molecular structure decomposition of TKX-50, resulting in the breakage of the original crystal. However, it is difficult for ABTOX to grow due to the solid state intermolecular forces in the growth process, and a microcrystal cluster was formed with an original crystal habit framework.

The packing diagram of ABTOX viewed from the $b$-axis direction is shown in Fig. 6. The hydrogen bonds (HBs) in ABTOX are shown in Table 2 and Fig. 7. It can be seen that there are four HBs: N8-H8A $\cdots \mathrm{O} 1, \mathrm{~N} 8-\mathrm{H} 8 \mathrm{~B} \cdots \mathrm{O} 1, \mathrm{~N} 9-\mathrm{H} 9 \cdots \mathrm{O} 1$ and $\mathrm{N} 10-\mathrm{H} 10 \cdots \mathrm{O} 1$. The HBs are formed between the $\mathrm{C}_{2} \mathrm{O}_{2} \mathrm{~N}_{8}{ }^{2-}$ anions and the $\mathrm{NH}_{4}{ }^{+}$cations. The possible HB acceptors are the

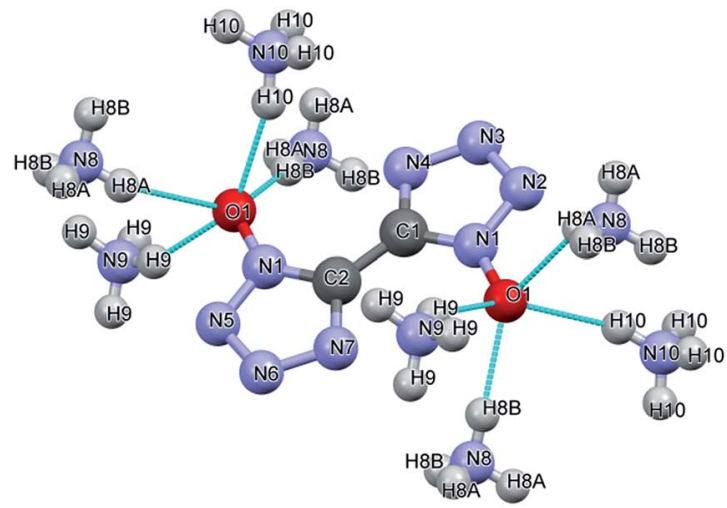

Fig. 7 The hydrogen bonds of ABTOX.

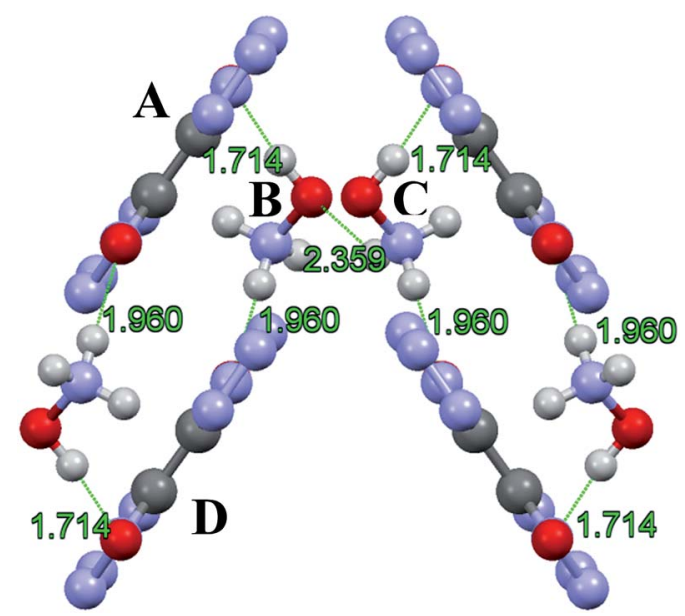

Fig. 8 The hydrogen bonds of TKX-50.

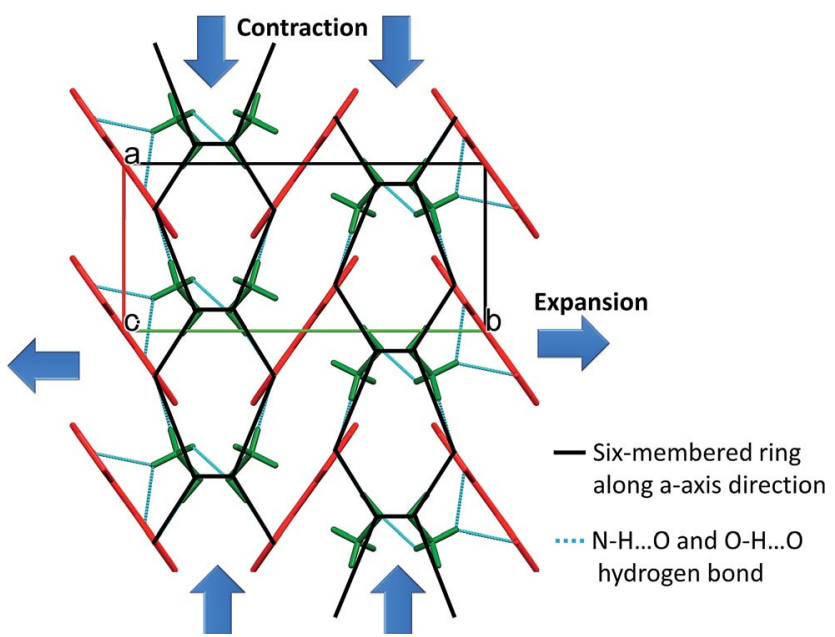

Fig. 9 The packing diagram of TKX-50 (viewed from the a-axis direction).

$\mathrm{O}$ atoms of the $\mathrm{C}_{2} \mathrm{O}_{2} \mathrm{~N}_{8}{ }^{2-}$ anions, in which each $\mathrm{O}$ atom is a quaternary $\mathrm{HB}$ acceptor, and the $\mathrm{NH}_{4}{ }^{+}$cations act as donors. The $\mathrm{C}_{2} \mathrm{O}_{2} \mathrm{~N}_{8}{ }^{2-}$ anions and $\mathrm{NH}_{4}{ }^{+}$cations are all layer packed 


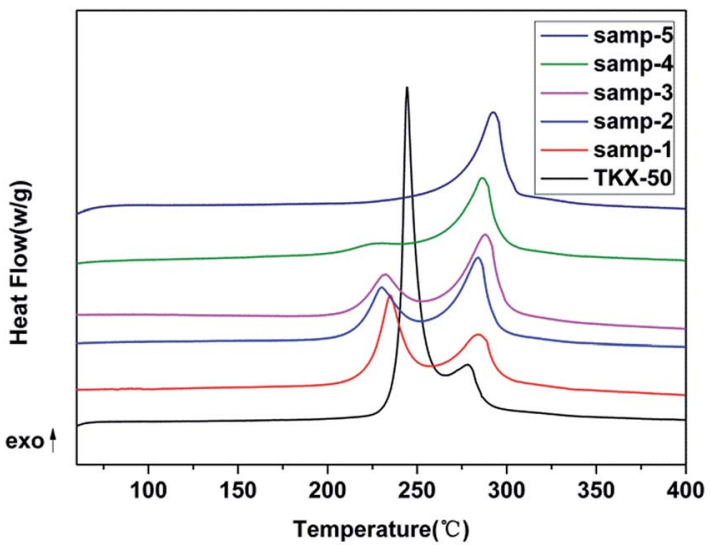

Fig. $10 \mathrm{TG}$ thermograms of TKX-50 and samples after primary decomposition.

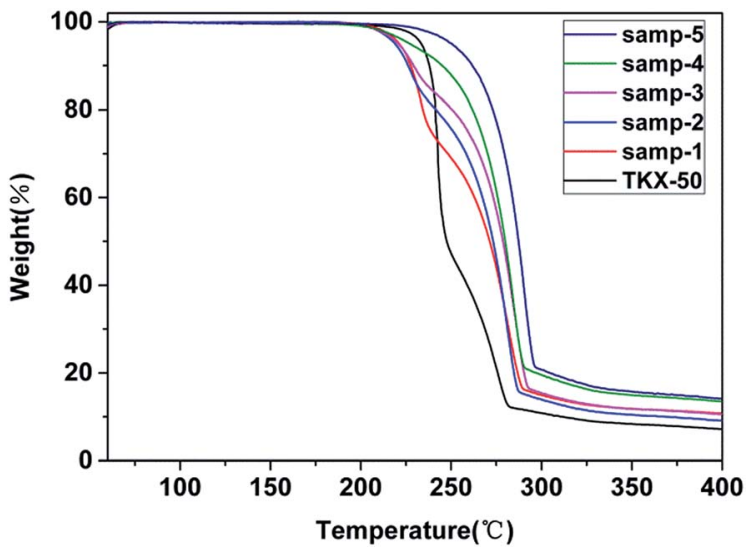

Fig. 11 DSC thermograms of TKX-50 and samples after primary decomposition.

Table 3 Thermodynamic parameters ${ }^{a}$

\begin{tabular}{lllll}
\hline Samples & $T_{1}\left({ }^{\circ} \mathrm{C}\right)$ & $T_{2}\left({ }^{\circ} \mathrm{C}\right)$ & $\Delta H_{1}\left(\mathrm{~J} \mathrm{~g}^{-1}\right)$ & $\Delta H_{2}\left(\mathrm{~J} \mathrm{~g}^{-1}\right)$ \\
\hline TKX-50 & 244.3 & 278.4 & 1564.0 & 370.1 \\
Samp-1 & 235.0 & 284.2 & 782.9 & 771.6 \\
Samp-2 & 230.3 & 284.0 & 517.9 & 859.0 \\
Samp-3 & 230.0 & 284.0 & 442.7 & 877.4 \\
Samp-4 & 230.0 & 286.3 & 250.8 & 911.4 \\
Samp-5 & - & 292.3 & - & 998.4
\end{tabular}

${ }^{a}$ Samp-1, samp-2, samp-3, samp-4 and samp-5 represent the materials after primary thermal decomposition under isothermal conditions at 190, 192, 194, 196 and $198{ }^{\circ} \mathrm{C}$, respectively; $T_{1}$ : the peak temperature of primary decomposition; $T_{2}$ : the peak temperature of secondary decomposition; $\Delta H_{1}$ : the enthalpy of primary decomposition; $\Delta H_{2}$ : the enthalpy of secondary decomposition.

when viewed from the $b$-axis direction. One $\mathrm{C}_{2} \mathrm{O}_{2} \mathrm{~N}_{8}{ }^{2-}$ anion is encompassed by eight $\mathrm{NH}_{4}{ }^{+}$cations and there are eight HBs formed. The shorter $\mathrm{H} \cdots \mathrm{O}$ distances and bigger $\mathrm{HB}$ bond angles contribute to the formation of strong HBs, which are beneficial to the stabilization of ABTOX.

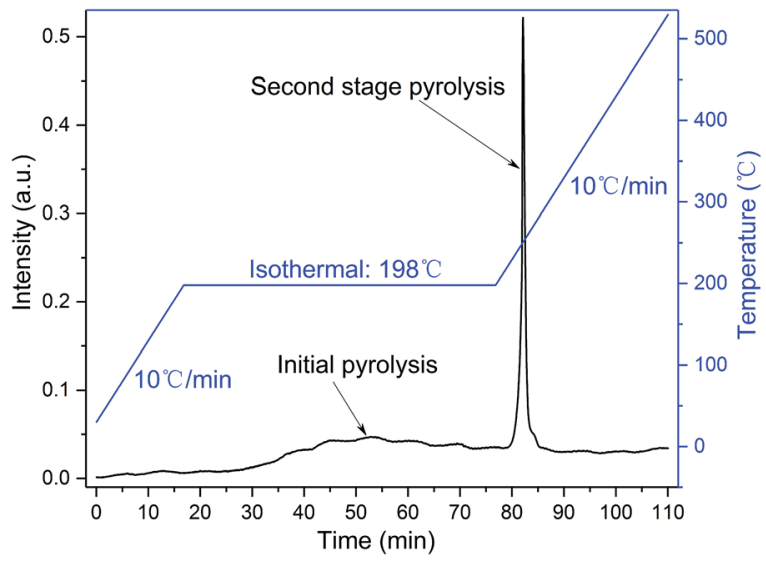

Fig. 12 The FTIR signal spectrum and corresponding temperature program (the blue line represents the temperature program and the black line represents the FTIR signal spectrum of the TKX-50 thermal decomposition gas products).

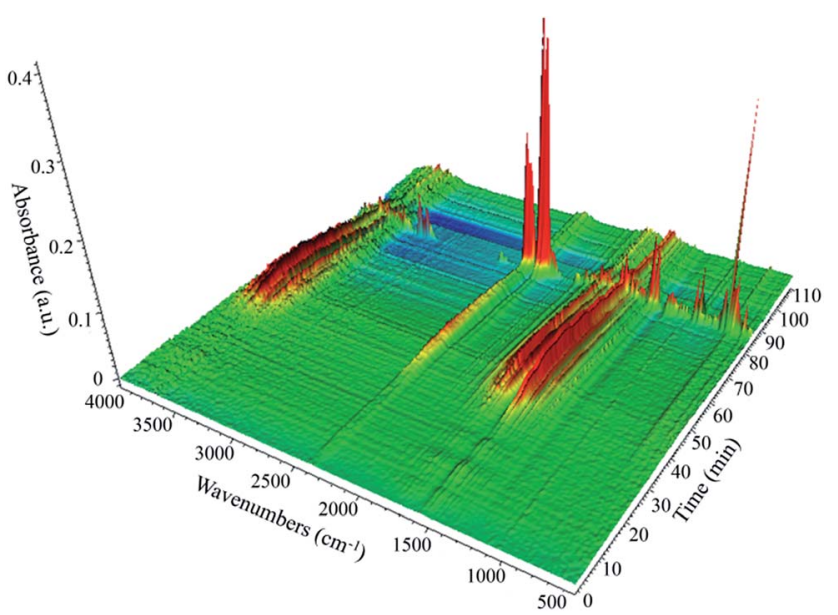

Fig. 13 The three-dimensional FTIR spectra of the TKX-50 thermal decomposition gas products.

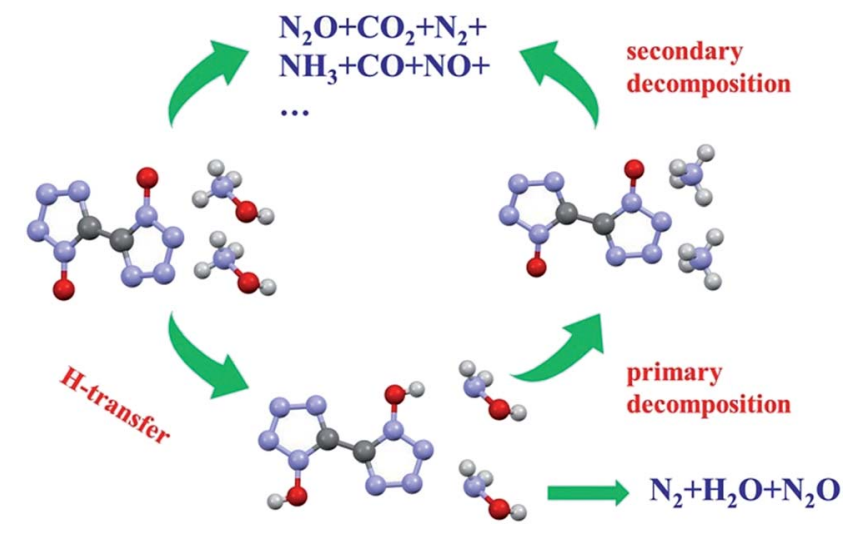

Fig. 14 The proposed thermal decomposition mechanism of TKX-50.

TKX-50 is monoclinic, has strong hydrogen bonding between the cations and anions, mainly through the $\mathrm{H}$ atom on $\left(\mathrm{NH}_{3} \mathrm{OH}\right)^{+}$and the $\mathrm{O}$ atoms and $\mathrm{N}$ atoms on the bistetrazoles, 
and the minimum hydrogen bonding distance is $1.714 \AA$. The HBs of TKX-50 are shown in Fig. 8. The packing mode of the crystal cell under thermal expansion will be influenced by the strong hydrogen bonding. The packing diagram of TKX-50 along the $a$-axis direction is shown in Fig. 9. It is found that a six-membered ring unit is formed by strong hydrogen bonding and these units accumulate gradually along the $a$-axis direction. From the interactions between the cations and anions, the hydrogen bonding between $\mathrm{A}$ and $\mathrm{B}$ and $\mathrm{B}$ and D are stronger than the hydrogen bonding between $\mathrm{B}$ and $\mathrm{C}$. Therefore, under thermal stimulation, the vibration of TKX-50 also increases. The weaker part of the six-membered ring structure is elongated first, which leads to the flattening of the six-membered ring and the $a$-axis direction of the crystal cell is contracted, thus the $a$ axis exhibits NTE. The constant expansion of the $b$-axis and sustained compression of the $a$-axis lead to a shortening of the distance between $\mathrm{A}$ and $\mathrm{B}$ and between $\mathrm{B}$ and D. As the temperature keeps rising and the distance is shortened to a certain extent, $\mathrm{H}$-transfer is induced, in which the $\mathrm{H}$ atom of $\mathrm{NH}_{3} \mathrm{OH}^{+}$transfers to the $\mathrm{O}$ atom of bistetrazole and $\mathrm{NH}_{2} \mathrm{OH}$ and $1 H, 1^{\prime} H$-5, $5^{\prime}$-bistetrazole-1, $1^{\prime}$-diol (BTO) are formed. However, $\mathrm{NH}_{2} \mathrm{OH}$ is very unstable at room temperature, and $\mathrm{NH}_{2} \mathrm{OH}$ continues to decompose and form $\mathrm{NH}_{3}$ and $\mathrm{H}_{2} \mathrm{O}$, etc. at high temperatures. Meanwhile, A and D gradually become parallel to the $b$-axis due to the reduction of the resistance between $\mathrm{A}$ and D. $\mathrm{NH}_{3}$ then combines with BTO to form ABTOX.

\subsection{The secondary decomposition of TKX-50}

Thermogravimetric-differential scanning calorimetry (TG-DSC) was employed to analyse secondary decomposition of TKX-50. The obtained TG thermograms are shown in Fig. 10 and the DSC thermograms are shown in Fig. 11.

From the TG-DSC curve of raw TKX-50, two exothermic decomposition peaks are obvious. The thermodynamic parameters are shown in Table 3. The enthalpy of the first decomposition process is much greater than that of the second process. The peak temperature of the first exothermic peak is $244{ }^{\circ} \mathrm{C}$ and the second is $278{ }^{\circ} \mathrm{C}$. Compared with the TG-DSC curve of raw TKX-50, it is found that the enthalpy value of the first exothermic peak decreases with the increasing heat treatment temperature and that of the second peak increases. Moreover, the peak temperature of the samples after primary decomposition of raw TKX-50 is lower than that of TKX-50. The main intermediate product after primary thermal decomposition is stable.

It is deduced that the decrease in enthalpy is caused by the fact that TKX-50 is decomposed slowly in the process of primary decomposition, accompanied by the release of energy. Moreover, the conversion degree is different due to the different isothermal temperature at the same time and the conversion degree of TKX-50 to the intermediate product is $24.30 \%$ at $190{ }^{\circ} \mathrm{C}$ and $100 \%$ at $198{ }^{\circ} \mathrm{C}$ (Fig. 3). Therefore, the enthalpy of the first decomposition gradually decreased with the increase in isothermal temperature. Meanwhile, it is deduced that the advanced peak temperature of the samples after heat treatment is caused by the fact that the primary and secondary thermal decompositions of TKX-50 are influenced by each other. Also, the integrity of the crystal structure is destroyed during primary decomposition which accelerates the thermal decomposition rate and increases the peak temperature of secondary decomposition.

\subsection{The gaseous decomposition products and the thermal decomposition mechanism of TKX-50}

TG-FTIR technology was applied to analyse the gaseous decomposition products of each process. The FTIR signal spectrum and the corresponding temperature program are shown in Fig. 12 and the three-dimensional FTIR spectra of the TKX-50 thermal decomposition gas products are shown in Fig. 13. It is found that the primary decomposition of TKX-50 yields large amounts of $\mathrm{H}_{2} \mathrm{O}$ at $198{ }^{\circ} \mathrm{C}$, which is confirmed by the characteristic peaks for water vapor in the infrared spectrum at $4000-3500 \mathrm{~cm}^{-1}$ and $2000-1500 \mathrm{~cm}^{-1}$. It is also consistent with the result that the liquid forms bubbles that emerge from the crystal as shown in Fig. 1. The FTIR spectra show that the primary decomposition is mainly the decomposition of $\mathrm{NH}_{3} \mathrm{OH}^{+}$to form $\mathrm{H}_{2} \mathrm{O}, \mathrm{NH}_{3}, \mathrm{~N}_{2}$ and $\mathrm{N}_{2} \mathrm{O}$, and that $\mathrm{NH}_{3}$ combines with BTO to form ABTOX, which is consistent with the previous analysis. In addition, when the temperature continues to rise, ABTOX mainly decomposes into $\mathrm{N}_{2} \mathrm{O}, \mathrm{CO}_{2}, \mathrm{~N}_{2}$, etc.

The proposed thermal decomposition mechanism of TKX-50 is shown in Fig. 14. Under thermal stimulation, crystal expansion occurs first and is followed by H-transfer, which accelerates the primary decomposition of TKX-50. As the temperature increases, the primary decomposition becomes more intense, and ABTOX gradually forms by the combination of $\mathrm{NH}_{3}$ and BTO, accompanied by the generation of $\mathrm{H}_{2} \mathrm{O}, \mathrm{N}_{2}$ and $\mathrm{N}_{2} \mathrm{O}$. When the temperature continues to rise, ABTOX eventually breaks down into small molecular gaseous products such as $\mathrm{N}_{2} \mathrm{O}, \mathrm{CO}_{2}$, $\mathrm{N}_{2}$, etc.

\section{Conclusions}

In this paper, the crystal structure transformation of TKX-50 during heat treatment was analysed by means of in situ XRD, TG-DSC and TG-FTIR. It was found that only anisotropic thermal expansion occurs from $30{ }^{\circ} \mathrm{C}$ to $175{ }^{\circ} \mathrm{C}$, during which the $a$-axis and $\beta$ angle exhibit NTE and the $b$-axis, $c$-axis and unit cell volume exhibit PTE, leading to a change of intermolecular force and the expansion and flipping of some molecules. In particular, the NTE of the $a$-axis results in a shorter distance between the cations and dianions, which induces hydrogen transfer, which then accelerates primary decomposition of TKX50. With the increasing temperature primary decomposition occurred and the intermediate product ABTOX was formed, which was confirmed by single $\mathrm{XRD}$, and we deduced the process from TKX-50 to ABTOX. The morphology change from thermal expansion to primary decomposition was obtained by HSM and the results are consistent with each process. When the temperature continues to rise to $270{ }^{\circ} \mathrm{C}$, secondary decomposition occurrs. The gas products were also obtained by TG-FTIR 
and the decomposition mechanism was proposed. In short, TKX-50 has undergone thermal expansion, primary decomposition and secondary decomposition under heat stimulation. It can be concluded that energetic ionic salts often have multistep thermal decomposition processes because of their crystal structure. Just for this reason, it is very important to control the compatibility of materials with other materials in order to ensure they are suitable for a particular application and effectively avoid structural deterioration.

\section{Conflicts of interest}

There are no conflicts to declare.

\section{Acknowledgements}

This work was financially supported by the Natural Science Foundation of China (No. 11572295, 11372290 and 11472252).

\section{References}

1 Y.-H. Joo and J. M. Shreeve, J. Am. Chem. Soc., 2010, 132(42), 15081-15090.

2 Y.-H. Joo and J. M. Shreeve, Angew. Chem., Int. Ed., 2010, 49, 7320-7323.

3 M. J. Crawford, T. M. Klapotke, F. A. Martin, C. M. Sabate and M. Rusan, Chem.-Eur. J., 2011, 17, 1683-1695.

4 T. M. Klapotke, P. Mayer, A. Schulz and J. J. Weigand, J. Am. Chem. Soc., 2005, 127, 2032-2033.

5 T. M. Klapotke, C. M. Sabate and M. Rasp, J. Mater. Chem., 2009, 19, 2240-2252.

6 H. X. Gao and J. M. Shreeve, Chem. Rev., 2011, 111, 73777436.

7 T. M. Klapotke and C. MiroSabate, Chem. Mater., 2008, 20, 3629-3637.

8 A. Mehrkesh and A. T. Karunanithi, ACS Sustainable Chem. Eng., 2013, 1, 448-455.

9 T. M. Klapotke, K. Karaghiosoff, P. Mayer, A. Penger and J. M. Welch, Propellants, Explos., Pyrotech., 2006, 31, 188-195.

10 M. von Denffer, T. M. Klapotke, G. Kramer, G. Spieß, J. M. Welch and G. Heeb, Propellants, Explos., Pyrotech., 2005, 30, 191-195.

11 Z. Zeng, H. X. Gao, B. Twamley and J. M. Shreeve, J. Mater. Chem., 2007, 17, 3819-3826.

12 T. M. Klapotke and F. X. Steemann, Propellants, Explos., Pyrotech., 2010, 35, 114-129.

13 P. He, J. G. Zhang, X. Yin, J. T. Wu, L. Wu, Z. N. Zhou and T. L. Zhang, Chem.-Eur. J., 2016, 22, 7670-7685.

14 C. F. Ye, J. C. Xiao, T. Brendan and J. M. Shreeve, Chem. Commun., 2005, 2750-2752.
15 J. C. Galvez-Ruiz, G. Holl, K. Karaghiosoff, T. M. Klapotke, K. Loehnwitz, P. Mayer, H. Noeth, K. Polborn, C. J. Rohbogner, M. Suter and J. J. Weigand, J. Inorg. Chem., 2005, 44, 4237-4253.

16 R. S. Damse and A. K. Sikder, J. Hazard. Mater., 2009, 166, 967-971.

17 N. Fischer, T. M. Klapotke, M. Reymann and J. Stierstorfer, Eur. J. Inorg. Chem., 2013, 12, 2167-2180.

18 N. Fischer, D. Fischer, T. M. Klapotke, D. G. Pierccey and J. Stierstorfer, J. Mater. Chem., 2012, 22, 20418-20422.

19 J. L. Gottfried, T. M. Klapotke and T. G. Witkowski, Propellants, Explos., Pyrotech., 2017, 42, 353-359.

20 N. Fischer, T. M. Klapotke, S. M. Musanic, J. Stierstorfer and M. Suceska, New Trends Res. Energ. Mater., 2013, 16, 574-585.

21 H. F. Huang, Y. M. Shi and J. Yang, J. Therm. Anal. Calorim., 2015, 121, 705-709.

22 L. B. Xiao, F. Q. Zhao, Y. Luo, N. Li, H. X. Gao, Y. Q. Xue, Z. X. Cui and R. Z. Hu, J. Therm. Anal. Calorim., 2016, 123, 653-657.

23 H. Niu, S. S. Chen, S. H. Jin, L. J. Li, B. C. Jin, Z. M. Jiang, J. W. Ji and Q. H. Shu, J. Therm. Anal. Calorim., 2016, 126, 473-480.

24 Z. A. Dreger, C. J. Breshike and Y. M. Gupta, Chem. Phys. Lett., 2017, 679, 212-218.

25 Z. A. Dreger, A. I. Stash, Z. G. Yu, Y. S. Chen and Y. C. Tao, J. Phys. Chem. C, 2017, 121, 5761-5767.

26 Q. An, W. G. Liu, W. A. Goddard and S. V. Zybin, J. Phys. Chem. C, 2015, 119, 2196-2207.

27 L. Y. Meng, Z. P. Lu, X. F. Wei, X. G. Xue, Y. Ma, Q. Zeng, G. J. Fan, F. D. Nie and C. Y. Zhang, CrystEngComm, 2016, 18, 2258-2267.

28 V. P. Sinditskii, S. A. Filatov, V. I. Kolesov, K. O. Kapranov, A. F. Asachenko, M. S. Nechaev, V. V. Lunin and N. I. Shishov, Thermochim. Acta, 2015, 614, 85-92.

29 N. V. Muravyev, K. A. Monogarov, A. F. Asachenko, M. S. Nechaev, I. V. Ananyev, I. V. Fomenkov, V. G. Kiselev and A. N. Pivkina, Phys. Chem. Chem. Phys., 2017, 19, 436449.

30 Z. P. Lu, X. G. Xue, L. Y. Meng, Q. Zeng, Y. Chi, G. J. Fan, H. Z. Li, Z. M. Zhang, F. D. Nie and C. Y. Zhang, J. Phys. Chem. C, 2017, 121, 8262-8271.

31 C. Xue, J. Sun, B. Kang, Y. Liu and X. F. Liu, Propellants, Explos., Pyrotech., 2010, 35, 333-338.

32 Y. Liu, S. C. Li, Z. S. Wang, J. J. Xu, J. Sun and H. Huang, Cent. Eur. J. Energ. Mater., 2016, 13, 1023-1037.

33 P. Kroll, M. Andrade, X. H. Yan, E. Ionescu, G. Miehe and R. Riedel, J. Phys. Chem. C, 2012, 116, 526-531. 